\title{
An empirical investigation of gist helpfulness in online reviews
}

\author{
Sanjay Bhāle \\ Indira Institute of Management, \\ Savitribai Phule Pune University (SPPU), India \\ Ketan Tongare \\ Vishwakarma Institute of Management, \\ Savitribai Phule Pune University (SPPU), India
}

\section{Keywords}

e-commerce; gist helpfulness; online review; online recommendations; purchase behaviors

\begin{abstract}
The online-purchase trends suggest that consumers' online reviews have become very important for customers and the sellers in purchase decisions and product sales respectively. Although the significance of online reviews has been examined, there are research gaps in studies on how to make title of online reviews helpful. The paper explores the traits that influence the formation of title of online reviews.

The study proposes gist helpfulness for the title of online reviews adopting elements such as online recommendation, online reviewer, and online review timeline, online review indicator. Our analysis of data from survey of 528 customers shows that daily use of internet positively influences gist helpfulness. The analysis was conducted through binary logistic regression. It is found that review depth and online reading experience have significance over gist helpfulness. The approach in this study is empirical where it attempts to improvise selection of reading reviews based on titles. The scope of the study is as such that it can be adopted by online companies to upgrade the current online review system and enrich customer experience to main tain relationship with their users. Besides, this paper aims to develop a normative model considering important strategic issues to develop an insight related to consumer reviews.
\end{abstract}

Corresponding author: Sanjay Bhāle

Email addresses for corresponding author: sanjay.bhale@indiraiimp.edu.in

First submission received: $25^{\text {th }}$ March 2018

Revised submission received: $10^{\text {th }}$ May 2018

Accepted: 28th May 2018

\section{Introduction}

Online customer reviews have endeavored influence on customers' purchase decisions when shopping online and has given modern emphasis to the concept of word-of-mouth. Online reviews play significant role in making certain degree of construct, supported by the level of cognizance and technical orientation of the consumer in a given interactive digital environment. The enormous quantity, heterogeneity and receptiveness of online reviews have contributed to their appeal and growing popularity. Voluminous information is available regarding products reviews online and reading all the reviews is laborious and time consuming for customers. Thus, most customers choose to read reviews selectively. The online sellers invite users of their products to post personal product evaluations on the sellers' and it helps them correct their promotional strategy accordingly.

According to the theory of selective attention, people react to messages selectively because individual possess finite information processing capacity (Treisman, 1969). Similarly, people pay selective attention to online reviews. People look for instantaneous cues that enable them to decide whether to read a review or not. One such indicator is the title of online reviews. Titles of online reviews grab the attention of customers. Salehan and Kim (2016) found reviews receive more readerships with titles having higher levels of positive sentiment whereas length of the title is negatively related to the readership.

Each review has a title and body text. However, despite prior investigations related review body text in online reviews we find the title of online reviews component is mostly unexplored in this domain. 
This study contributes to the existing body of knowledge in a peculiar way as it attempts to improvise the process for selection of reading reviews based on titles.

Gist helpfulness may be defined as important pieces of information about online reviews that makes it helpful instantaneously. The study proposes gist helpfulness for the title of online reviews adopting elements such as online recommendation, online reviewer, and online review timeline, online review indicator.

The paper proceeds as follows:

Developing the theoretical foundation for gist helpfulness.

Developing the research model and hypothesis.

Analyzing the research model using binary logistic regression as dependent variable gist helpfulness is dichotomous variable (Yes or No).

\section{Related literature}

With the rise of online reviews, many people believe that online reviews could be a good alternative for complete word of mouth (WOM) and could also influence consumers 'decisions. Previous empirical findings support the idea. Godes and Mayzlin (2004) found positive association between eWOM and TV shows viewership. Liu (2006) studied movie reviews and found that online movie reviews propose important explanatory power for both cumulative and weekly box office revenues. This suggests that customers make offline purchase decisions established from online information and some forms of eWOM are proxies for overall WOM. Various studies attempted to determine the relation between online reviews and product sales, and they found mixed findings. Chevalier and Mayzlin (2006) found online consumer ratings greatly impact product sales in case of books. Zhang and Dellarocas (2006) obtained similar results in case of movie industry. In contrast, Chen et al. (2004) and Duan et al. (2008) found that online reviews do not impact sales but serve only as predictors.

A customer is always in search of quality information in online environment. The quality of online reviews has a positive impact on consumers' purchasing plan and purchasing intention increases with an increment in the number of reviews (Park et al., 2007). Lee et al. (2011) results show that greater perceived credibility of online consumer reviews among potential consumers leads to higher purchase intention. Consumer presume online reviews to be more credible when the review contains detailed information in case of search product whereas for experience product consumer determines the credibility of review by judging the level of reviewer agreement with a review (Jimenez and Mendoza, 2013). Xia and Bechwati (2008) study suggest that the differential effect of online reviews is slightly due to readers'(information seekers) cognitive personalization. When information seekers sense rapport with the reviewer, they perceive the review more trustworthy and useful and give more influence over their purchase intentions. In online word of mouth, reviews help notify future consumer and reduce doubt surrounding the shopping experience (Dellarocas, 2003). However, there are large numbers of reviews available to read. Consumers often require only a limited set of helpful reviews, and many online vendors enforce mechanisms to identify reviews that customers observe as most helpful (Cao et al., 2011; Mudambi and Schuff, 2010). A better understanding of perceived review helpfulness offers definite perks to online retailers and review providers (Chen et al., 2008).

Several studies have been done on helpfulness of review (see Table1), Schindler and Bickart (2012) found the length of a consumer review to be positively linked to its perceived value to other consumers, but only to a point. Combination of reviewer and review features are significantly associated with the observed usefulness of reviews (Racherla and Friske, 2012). Huang et al. (2013) suggests consumers perceive product reviews written by customers more helpful than written by experts.

Table1. Prior Studies on the Helpfulness of Online Review

\begin{tabular}{|l|l|l|l|l|}
\hline Authors & Data & Sample size(N) & Method & Findings \\
\hline $\begin{array}{l}\text { Forman et al. } \\
(2008)\end{array}$ & Amazon (book) & 786 & Econometrics & $\begin{array}{l}\text { Sharing of geographical } \\
\text { location of reviewer has } \\
\text { positive effect on product sales }\end{array}$ \\
\hline $\begin{array}{l}\text { Mudambi \& } \\
\text { Schuff (2010) }\end{array}$ & $\begin{array}{l}\text { Amazon (search and } \\
\text { experience goods) }\end{array}$ & 1587 (reviews) & Econometrics & $\begin{array}{l}\text { Effect of review extremity on } \\
\text { helpfulness of reviews is } \\
\text { controlled by the product type }\end{array}$ \\
\hline
\end{tabular}

www.jbrmr.com A Journal of the Academy of Business and Retail Management (ABRM) 


\begin{tabular}{|c|c|c|c|c|}
\hline Zhang et al. (2010) & $\begin{array}{l}\text { Survey (software } \\
\text { program) }\end{array}$ & 150 & SEM & $\begin{array}{l}\text { Potential customers are more } \\
\text { responsive to reviews that are } \\
\text { perceived more helpful }\end{array}$ \\
\hline $\begin{array}{l}\text { Ghose \& Ipeirotis } \\
\text { (2011) }\end{array}$ & $\begin{array}{l}\text { Amazon (electronic } \\
\text { goods) }\end{array}$ & 411 & Econometrics & $\begin{array}{l}\text { Simple review will be more } \\
\text { helpful than a more } \\
\text { complicated one }\end{array}$ \\
\hline Schlosser (2011) & (movie, book) & 201 & Experiment & $\begin{array}{l}\text { One sided argument is } \\
\text { perceived more helpful than } \\
\text { two sided arguments }\end{array}$ \\
\hline $\begin{array}{l}\text { Korfiatis et al. } \\
(2012)\end{array}$ & Amazon (book) & 37,221 (reviews) & Econometrics & $\begin{array}{l}\text { Review readability has more } \\
\text { effect on helpfulness ratio of } \\
\text { review than the length of } \\
\text { review }\end{array}$ \\
\hline $\begin{array}{l}\text { Cheung et al. } \\
\text { (2012) }\end{array}$ & Survey (not specified) & 99 & SEM & $\begin{array}{l}\text { Customers rely on source } \\
\text { credibility, review consistency, } \\
\text { and review sidedness while } \\
\text { evaluating online consumer } \\
\text { reviews }\end{array}$ \\
\hline Baek et al. (2013) & $\begin{array}{l}\text { Amazon (search and } \\
\text { experience goods) }\end{array}$ & 75,226 (reviews) & Econometrics & $\begin{array}{l}\text { Review rating, reviewer's } \\
\text { credibility, and content of } \\
\text { reviews influence the } \\
\text { helpfulness of reviews }\end{array}$ \\
\hline $\begin{array}{l}\text { Yin, D., Bond, S., } \\
\text { \& Zhang, H. } \\
(2014)\end{array}$ & Online stores & 78 & Experiment & $\begin{array}{l}\text { Anxious reviews considered to } \\
\text { be more helpful than angry } \\
\text { reviews }\end{array}$ \\
\hline $\begin{array}{l}\text { Zhu, L., Yin, G., \& } \\
\text { He, W. (2014) }\end{array}$ & Yelp(hotel) & 16,265(reviews) & Econometrics & $\begin{array}{l}\text { Review written by an opinion } \\
\text { leader (high expertise and } \\
\text { more online friends) does not } \\
\text { correspond to reception of } \\
\text { helpfulness votes }\end{array}$ \\
\hline
\end{tabular}

Source: Author

\section{Theoretical foundation for the model}

The paper forms a framework of gist helpfulness for the title of reviews and provides formulation of analysis and synthesis of the literature using comprehensive scope from journals of various disciplines; articles published online and research reports. The concepts are evolved iteratively based on the reviewed content. The researchers come with proposed gist helpfulness adopting elements online reviewer, online recommendation, Online Review Indicator and online review timeline (see Figure 1).

\section{a. Online reviewer}

The element 'Online reviewer' referred to as the name of the reviewer or reviewer identity. Forman et al. (2008) concludes that the combination of reviewers' identity with relevant information shapes the online community member's judgment about products and reviews. Xie et al. (2011) study indicates that the presence of personal identifying information positively affects the observed credibility of online reviews. Kusumasondjaja et al. (2012) suggests positive online reviews leads to higher initial trust than negative reviews when the identity of the reviewer is disclosed. Racherla and Friske (2012) demonstrated the significance of identity disclosure in online interaction enhances the ability of customers' information procurement. Liu and Park (2015) study reveals that reviewers' identity disclosure has a significant impact on review usefulness. 


\section{b. Online recommendation}

The element ' $\approx$ Like' referred as online recommendation made by the customer. Chen et al. (2004) results indicated that more recommendations are positively associated with sales at Amazon.com. Senecal and Nantel (2004) found that participants selected products twice when exposed to product recommendations as often as those who were not exposed to recommendations. Fagerstrom and Ghinea (2011) study suggests that other online customer recommendations have more impact on novice online shoppers than who shop more frequently.

\section{c. Online Review Indicator}

The element Online Review Indicator are the cues that consumer can select why he recommends a product. The cues are assigned with respective symbols. The consumer can select the type of cue according to the best fit to their review description. The symbols will be represented in the title of reviews. Evaluation pricing of the product $(£)$. It is the evaluation of consumer of value of the product with respect to price. Does the price tag justify the value of the product to the consumer? Do the benefits from the product during the life time usage of product outweigh the price paying for the product by the consumer? Evaluation execution of the product (). It is the evaluation of consumer how reliable and efficient is the product. The consumer who has inconvenience in tweaking and modifying to get peak performance out the product will not prefer this cue.

Evaluation feature of the product (Q)

It is evaluation of consumer the quality of material used in making the product. The aesthetics features of the product that defines the consumer in social environment.

Evaluation maintenance provided by the company of the product $(\$)$

It is the evaluation of consumer of the overall experience in terms of service provided by the company of the product. The post purchase services provided by the company.

\section{d. Online Review Timeline}

The element is 'online review timeline' of the review denotes the time frame of review in hours, days, months and year format. Cui et al. (2012) findings show that volume of reviews has significant effect on new product sales and it decreases with time. Similarly, Hu et al. (2008) demonstrates that impact of sales is a decreasing function of age of the product. Each review written by customer reveals additional information to a new customer. Thus, the cumulative effect of impact of reviews due to reviewer will be substantial when a product has fewer pre-existing reviews. Dellarocas (Dellarocas et al., 2007) showed that early volume of online reviews can be used as a proxy of early sales in case of movies. People talk more about movies immediately after watching them than as time goes by. Whereas, McAuley and Leskovec (2013) suggest that users' tastes and preferences change and evolve over time. As user consume additional products and gain experience, may influence change in his rating behavior.

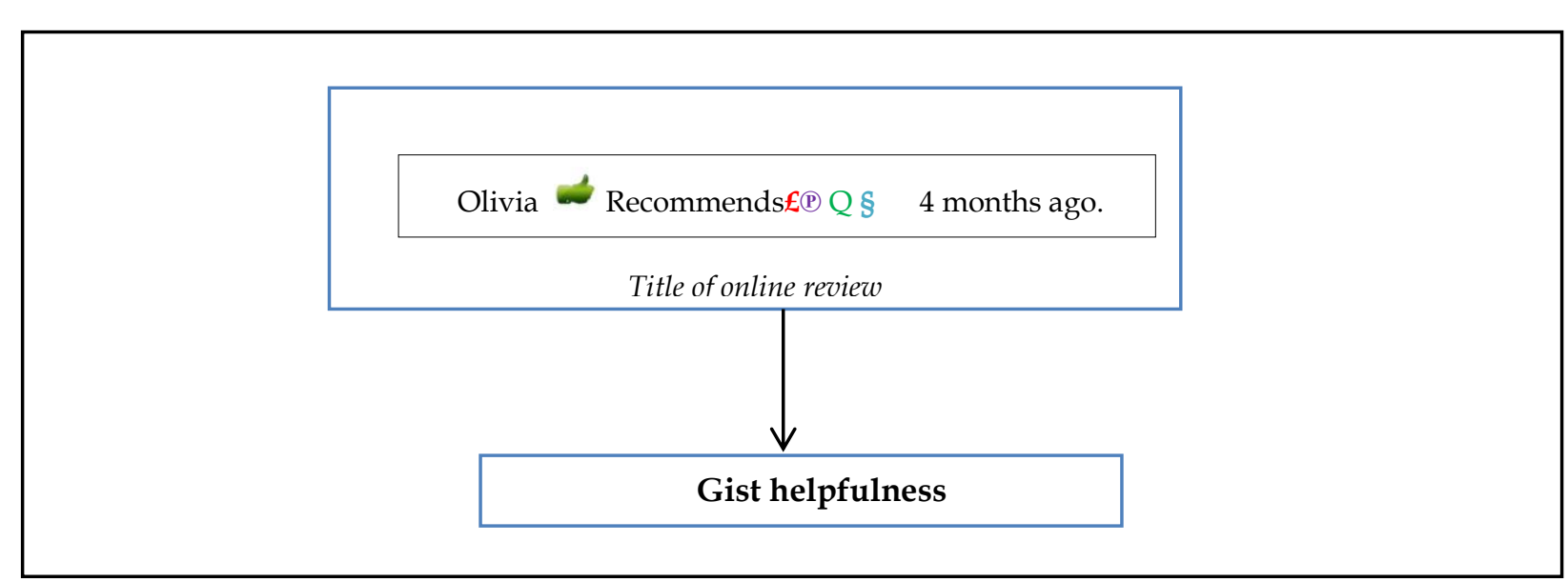

Figure 1: Theoretical foundation

Source: Author 


\section{Research model and Hypotheses \\ 4.1. Internet Experience}

The concept of Internet skills is one of various concepts that resulted from the rapid distribution of digital technologies into society. Internet skills can be considered a condition; for example, the skills to use cell phones or computers. An internet skill suggests indicating a set of basic skills in using Internet technology. How the consumers navigate and orient themselves in interactive digital environment. One internet skill is the approach adopted by consumer to fulfill his information needs and other is using internet as means for attaining specific goals. Consumers' ability to understand and adapt to a new feature online could be based on how much internet experience one has. We, therefore, propose the following set of hypotheses, where the first set refers to the internet experience that a consumer has. We propose with the daily use of internet consumers may adapt to gist helpfulness easily and may have positive effect on gist helpfulness. Access medium states the use of internet via different platforms i.e. PC, smartphone and tablet. As companies offer websites and App for same product services, usability, interface of new features designed could differ on different platforms i.e. on PC and smartphone. Access place refers to where the consumers most likely to use internet either for leisure or for work.

H1a: Consumers daily use of internet has positive effect on gist helpfulness.

H1b: Consumers access medium of internet moderates the effect on gist helpfulness.

H1c: Consumers access place of internet moderates the effect on gist helpfulness.

\subsection{Online review preference}

All styles of online reviews are available for a product. Consumers are likely to get attracted to reviews which are lengthy in nature. Detailed reviews written by former users contain information and may cover deep analysis of the product, thus consumers are fascinated by longer reviews. We propose consumers who prefer to read detailed, in depth reviews to be positively related to gist helpfulness. Many reviews have started adding on of attaching photos of bought product to the review. Users uploaded photos acts as visual cues for consumers and provides information that cannot be described. Thus, we propose consumers who prefer photos in reviews to be positively related gist helpfulness. Consumers gain information and doubt in their minds reduces as they gain knowledge of a product. Consumers read selected reviews as the number of reviews available for a product may have over thousand reviews. Although many review websites provide features such as most helpful, most liked, most recent and most read reviews, the choice of reading number of reviews remains with the consumer. Some consumers may only rely on product ratings to gain information of product and avoid reading reviews. Some consumers may gain information about the product reading a few reviews and some more than ten reviews. Consumer read number of reviews until they are satisfied about the information that they expect to gain from reviews and make a decision. This may also depend on the approach of finding reviews and selective nature of consumer. This may vary as consumer gains experience of reading reviews. Thus, we propose consumers with higher online review reading experience to be positively related to gist helpfulness. We, therefore, propose the second set of hypotheses, where the set refers to the online review preference that a consumer has.

H2a: Consumers prefer to read detailed reviews have positive effect on gist helpfulness.

$\mathrm{H} 2 \mathrm{~b}$ : Consumers prefer photos in reviews have positive effect on gist helpfulness.

$\mathrm{H} 2 \mathrm{c}$ : Consumers with higher online review reading experience have positive effect on gist helpfulness

For our study we strive for to better comprehend how to extemporize helpfulness in online reviews. Our research model (Figure 2) illustrates two factors that are internet experience and online review preference considers determining gist helpfulness. 
Figure 2: Research model

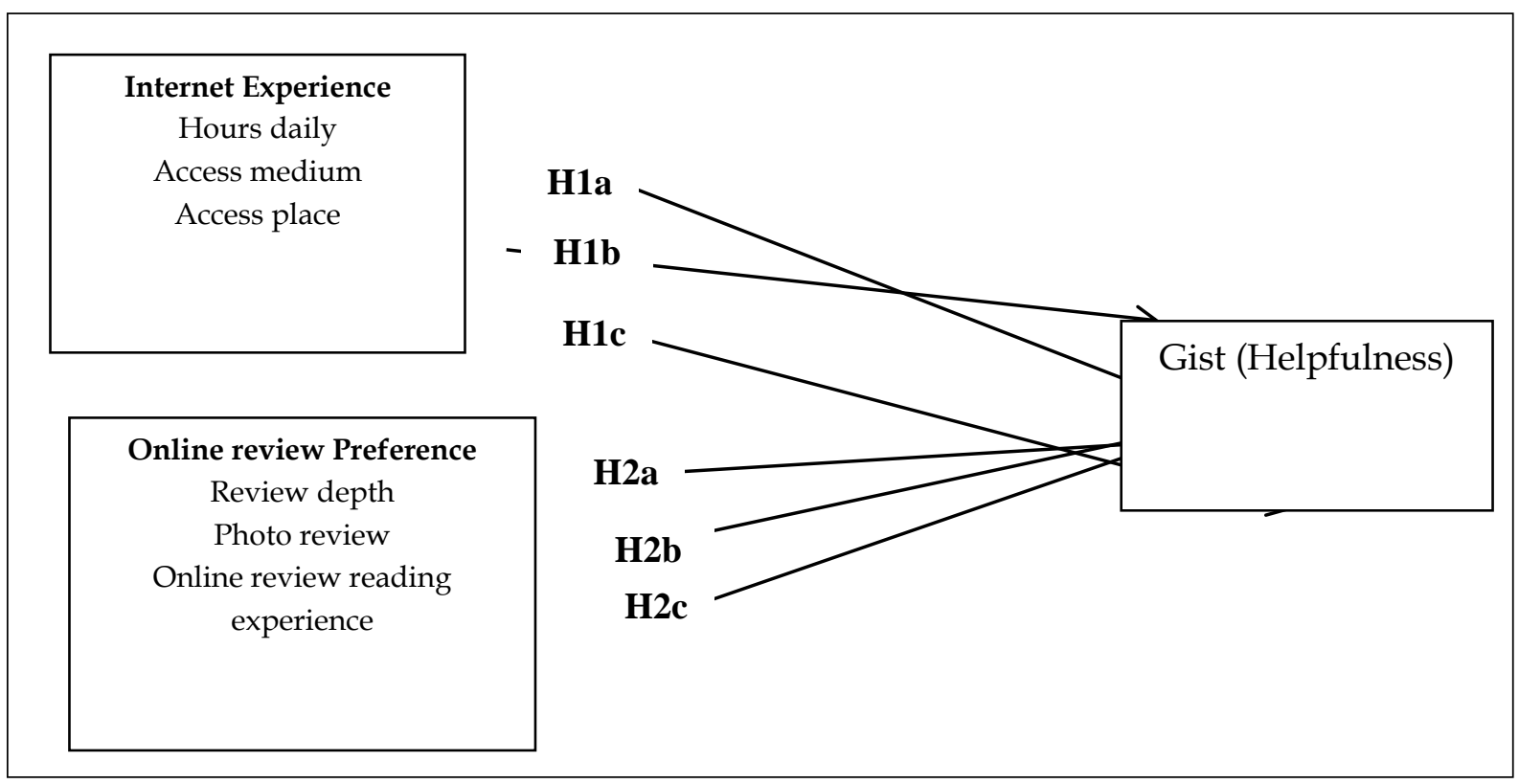

\section{Methodology}

\subsection{Procedure}

The unit of analysis in this study is the individual consumer who has experienced online reviews while purchasing products at online stores. Since the importance of this study is focused on investigating the relationship between gist helpfulness and online review preferences, internet experience is also among key factors in finding the adaptability and understanding a new online feature. As consumers' have attracted to online shopping on websites such as Amazon.com, the survey was not designed for specific target subjects. To collect the consumers' data, we built an online survey questionnaire. The form link was shared randomly to individuals and groups online via email, social websites such as facebook, WhatsApp. The survey period was from four to five weeks and the total number of participants was 528. Sample characteristics and Descriptive statistics of respondents profile shown in Table no 2. And Table no 3. Of 528 respondents, 41.7 percent were less than 21 years of age $(n=220), 54.7$ percent were 22-30 $(n=288), 1.5$ percent were 31-40 $(n=8), 0.8$ percent were $41-50(n=4), 1.5$ percent were 51 and above $(n=8)$. About 83.3 percent use smartphone for internet access $(n=440)$. About 76.5 percent find online reviews helpful for search products while buying online $(n=404)$. About 59.1 percent of respondents didn't prefer to read lengthy online reviews for products $(n=312)$. About 64.4 percent find photos in a review helpful $(n=340)$.

\begin{tabular}{|lll|}
\hline Table no 2. Sample Characteristics & \multicolumn{2}{l|}{} \\
\hline Characteristic & Number of respondents $(\mathrm{n}=528)$ & Percentage \\
\hline Sex & & \\
\hline Male & 360 & 68.2 \\
\hline Female & 168 & 31.8 \\
\hline Age & & \\
\hline Less than 21 & 220 & 41.7 \\
\hline $22-30$ & 288 & 54.5 \\
\hline $31-40$ & 8 & 1.5 \\
\hline $41-50$ & 4 & .8 \\
\hline 51 and above & 8 & 1.5 \\
\hline Qualification & & \\
\hline Undergraduate & 252 & 47.7 \\
\hline Graduate & 132 & 25.0 \\
\hline
\end{tabular}




\begin{tabular}{|c|c|c|}
\hline Post graduate & 144 & 27.3 \\
\hline \multicolumn{3}{|l|}{ Annual income } \\
\hline 3- 4 lakh & 352 & 66.7 \\
\hline 4-5 lakh & 68 & 12.9 \\
\hline 5 lakhs above & 108 & 20.5 \\
\hline \multicolumn{3}{|l|}{ Internet access medium } \\
\hline PC & 80 & 15.2 \\
\hline Tablet & 8 & 1.5 \\
\hline Smartphone & 440 & 83.3 \\
\hline \multicolumn{3}{|l|}{ Access place } \\
\hline At Home & 456 & 86.4 \\
\hline At work & 72 & 13.6 \\
\hline \multicolumn{3}{|l|}{ Hours daily } \\
\hline Less than 1 & 24 & 4.5 \\
\hline 1- 2 hours & 156 & 29.5 \\
\hline 3-4 hours & 180 & 34.1 \\
\hline 5-6 hours & 64 & 12.1 \\
\hline More than 6 hours & 104 & 19.7 \\
\hline \multicolumn{3}{|c|}{ Online review reading experience } \\
\hline No reviews & 28 & 5.3 \\
\hline $1-3$ reviews & 136 & 25.8 \\
\hline 4-7 reviews & 184 & 34.8 \\
\hline 7-10 reviews & 80 & 15.2 \\
\hline More than 10 reviews & 100 & 18.9 \\
\hline \multicolumn{3}{|l|}{ Product type } \\
\hline Search & 404 & 76.5 \\
\hline Experience & 124 & 23.5 \\
\hline \multicolumn{3}{|l|}{ Helpful vote } \\
\hline Yes & 240 & 45.5 \\
\hline No & 288 & 54.5 \\
\hline \multicolumn{3}{|l|}{ Review in depth } \\
\hline Yes & 216 & 40.9 \\
\hline No & 312 & 59.1 \\
\hline \multicolumn{3}{|l|}{ Photo in review } \\
\hline Yes & 340 & 64.4 \\
\hline No & 188 & 35.6 \\
\hline
\end{tabular}

Table no 3. Descriptive Statistics

\begin{tabular}{|l|l|l|l|l|l|l|}
\hline & $\mathrm{N}$ & Range|Minimum & Maximum & Mean & Std. Deviation & Variance \\
\hline Gender & 5281 & 0 & 1 & .32 & .466 & .217 \\
\hline Age & 5284 & 1 & 5 & 1.66 & .695 & .483 \\
\hline Qualification & 5282 & 1 & 3 & 1.80 & .842 & .710 \\
\hline income & 5282 & 1 & 3 & 1.54 & .812 & .659 \\
\hline Hours daily & 5284 & 1 & 5 & 3.13 & 1.171 & 1.372 \\
\hline Access place & 5281 & 0 & 1 & .14 & .343 & .118 \\
\hline Access medium & 5282 & 1 & 3 & 2.68 & .722 & .521 \\
\hline online review reading 5284 & 1 & 5 & 3.17 & 1.163 & 1.354 \\
\hline Product type & 5281 & 0 & 1 & .23 & .424 & .180 \\
\hline Helpful vote & 5281 & 0 & 1 & .55 & .498 & .248 \\
\hline review_indepth & 5281 & 0 & 1 & .41 & .492 & .242 \\
\hline photos_inreview & 5281 & 0 & 1 & .64 & .479 & .230 \\
\hline Valid N (listwise) & 528 & & & & & \\
\hline
\end{tabular}




\subsection{Measures}

The questionnaire was personalized for the dependent variable gist helpfulness. The dependent variable is dichotomous variable, the dependent variable gist helpfulness was coded as (Yes=1 and No $=0$ ). Respondents were asked to vote Yes or No for whether they found title of review helpful? The predicted event is that the respondent will vote for Yes (gist helpfulness). For independent variables review in depth, respondents were asked to vote Yes or No for whether they preferred to read lengthy online reviews before buying a product? Review in depth was coded as (Yes=1 and No $=0$ ). For photos in review respondents were asked to vote Yes or No for whether they preferred photos of bought product attached to the review? Photos in review was coded as (Yes=1 and No $=0)$. For access place, respondents were asked to vote from where they access internet more from Home or Work. Access place was coded as (Home $=0$ and Work $=1$ ). For Hours daily, respondents were asked for how many hours do they use internet daily? The hour's daily variable is a categorical, with five levels. SPSS allows us to select as the reference group either the group with the lowest numeric code or that with the highest numeric code. We have selected the lowest (first) code, 'less than 1 hour'. SPSS shows us the coding of the $k-1=4$ dummy variables that it has created in Appendix A: Categorical Variables Coding. Similarly, online review reading experience is a categorical variable, with five levels. We have selected the lowest (first) code, 'No reviews' as the reference group and 4 dummy variables were created for this variable. For access medium variable, 'PC' as the reference group and 2 dummy variables were created for this variable.

\subsection{Data analysis and results}

To analyze hypotheses $\mathrm{H} 1 \mathrm{a}$ through $\mathrm{H} 2 \mathrm{c}$, we tested the following regression model:

$\log ($ gist helpfulness $)=\beta 0+\beta 1$ (hours daily) $+\beta 2$ (access place) $+\beta 3$ (access medium) $+\beta 4$ (online reading experience) $+\beta 5$ (review in depth) $+\beta 6$ (photos in review) $+\varepsilon$.

We check the VIF of independent variables in table no 4 the result of analysis shows that multicollinearity is not a concern in this study.

\begin{tabular}{|c|c|c|c|}
\hline \multicolumn{4}{|c|}{ Table no 4. Collinearity Statistics of independent variables } \\
\hline & & Tolerance & VIF \\
\hline \multirow[t]{6}{*}{1} & review_indepth & .587 & 1.704 \\
\hline & photos_inreview & .609 & 1.642 \\
\hline & Hours daily & .936 & 1.069 \\
\hline & Access place & .807 & 1.239 \\
\hline & Access medium & .870 & 1.149 \\
\hline & online review reading & .961 & 1.041 \\
\hline
\end{tabular}

Then we proceeded with the model analysis. Table no 5. Shows Omnibus Tests of Model Coefficient which gives the result of the Likelihood Ratio (LR) test which indicates whether the inclusion of this block of variables contributes significantly to model fit. A p-value (sig) of less than 0.05 for block means that the block 1 model is a significant improvement to the block 0 model. The addition of variables reviews in depth, photos in review, hours daily, access place, access medium and online reading experience to the model has reduced the $-2-\log$ likelihood by 128.320 on 13 degree of freedom. $\chi^{2}(13$, $\mathrm{N}=528)=128.320, \mathrm{p}<0.001$.

\begin{tabular}{|c|c|c|c|c|}
\hline & & Chi-square & df & Sig. \\
\hline \multirow{3}{*}{ Step 1} & Step & 128.320 & 13 & .000 \\
\hline & Block & 128.320 & 13 & .000 \\
\hline & Model & 128.320 & 13 & .000 \\
\hline
\end{tabular}

From table no 6 we can conclude that between $21 \%$ and $29.4 \%$ of the variation in gist helpfulness can be explained by the model in block 1 . 


\begin{tabular}{|c|c|c|}
\hline \multicolumn{3}{|c|}{ Table no 6. Model Summary } \\
\hline Step & -2 Log likelihood & Cox \& Snell R Square|Nagelkerke R Square \\
\hline 1 & $572.302^{\mathrm{a}}$ & .216 \\
\hline
\end{tabular}

From table no 7 Our $H-L$ statistic has a significance of .262 which means that it is not statistically significant and therefore our model is quite a good fit. A goodness of fit of .262 indicating that binary logistic regression was a good choice for analysis of the proposed model. This desirable outcome of nonsignificance indicates that the model prediction does not significantly differ from the observed.

\begin{tabular}{|l|l|l|l|}
\hline \multicolumn{4}{|l|}{ Table no } \\
\hline Step & Hosmer and Lemeshow Test \\
\hline 1 & 10.050 & 8 & Sig. \\
\hline
\end{tabular}

From table no 8 Contingency Table for Hosmer and Lemeshow Test. The difference between the expected and observed in the column (gist helpfulness=Yes) is less suggests the more predictive capacity of the model.

\begin{tabular}{|c|c|c|c|c|c|c|}
\hline \multicolumn{7}{|c|}{ Table no 8. Contingency Table for Hosmer and Lemeshow Test } \\
\hline & & \multicolumn{2}{|c|}{ gist helpfulness $=$ No } & \multicolumn{2}{|c|}{ gist helpfulness $=$ Yes } & \multirow[t]{2}{*}{ Total } \\
\hline & & Observed & Expected & Observed & Expected & \\
\hline \multirow[t]{10}{*}{ Step 1} & 1 & 46 & 43.708 & 8 & 10.292 & 54 \\
\hline & 2 & 38 & 37.334 & 20 & 20.666 & 58 \\
\hline & 3 & 28 & 27.307 & 24 & 24.693 & 52 \\
\hline & 4 & 24 & 24.624 & 30 & 29.376 & 54 \\
\hline & 5 & 20 & 20.103 & 32 & 31.897 & 52 \\
\hline & 6 & 10 & 16.424 & 42 & 35.576 & 52 \\
\hline & 7 & 16 & 12.293 & 36 & 39.707 & 52 \\
\hline & 8 & 8 & 7.743 & 42 & 42.257 & 50 \\
\hline & 9 & 2 & 5.358 & 46 & 42.642 & 48 \\
\hline & 10 & 8 & 5.107 & 48 & 50.893 & 56 \\
\hline
\end{tabular}

From table no 9 Classification Table In this study, $82.9 \%$ say Yes and $56.0 \%$ for No for dependent variable i.e. gist helpfulness. Overall $72.7 \%$ say that they found the model helpful. This is a considerable improvement on the $62.1 \%$ classification with the constant model Block 0 , so we know that the model with predictors is a significantly better model. The predictive capacity of the model has increased by $10.6 \%$ to $72.7 \%$.

Table no 9. Classification Table (Block 1: Method = Enter)

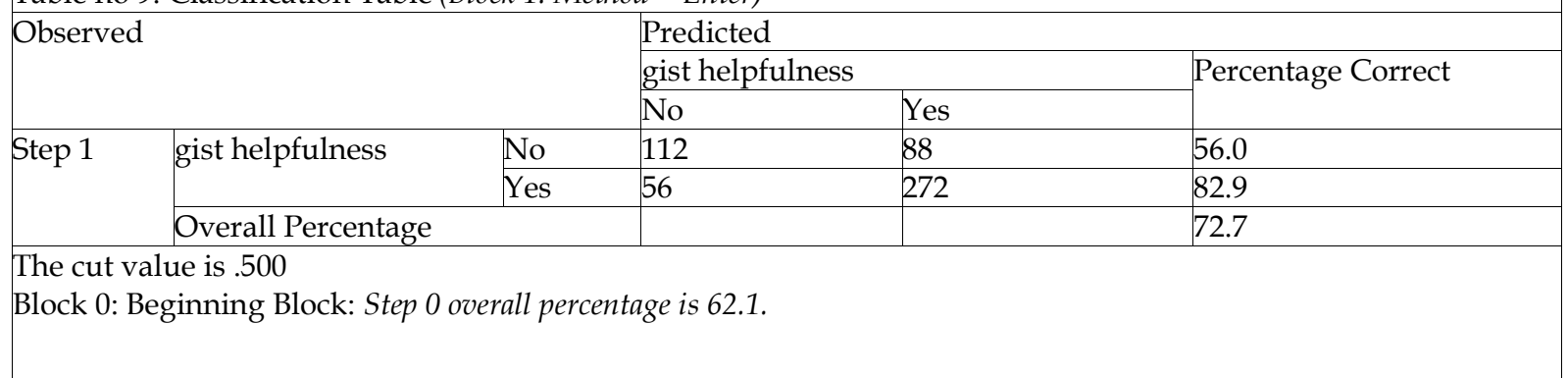

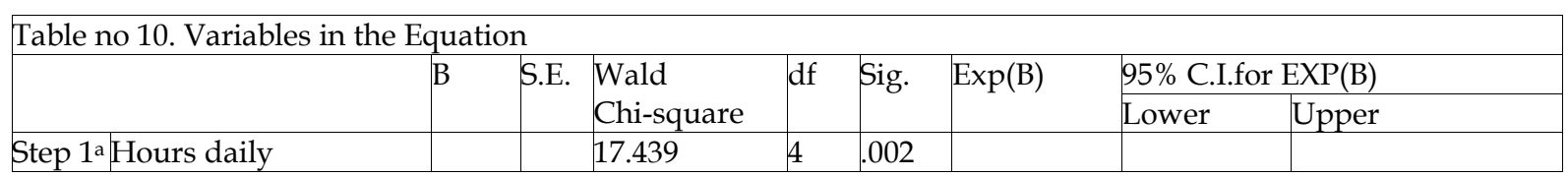




\begin{tabular}{|c|c|c|c|c|c|c|c|c|}
\hline Hours daily (1) & .432 & .527 & .672 & 1 & .412 & 1.541 & .548 & 4.329 \\
\hline Hours daily (2) & .936 & .515 & 3.308 & 1 & .069 & 2.549 & .930 & 6.989 \\
\hline Hours daily (3) & .871 & .590 & 2.182 & 1 & .140 & 2.390 & .752 & 7.595 \\
\hline Hours daily (4) & -.213 & .541 & 155 & 1 & .694 & .808 & .280 & 2.333 \\
\hline Access place (1) & .612 & .339 & 3.255 & 1 & .071 & 1.844 & .949 & 3.585 \\
\hline Access medium & & & .269 & 2 & .874 & & & \\
\hline Access medium (1) & .402 & 1.103 & 3.133 & 1 & .715 & 1.495 & .172 & 12.992 \\
\hline Access medium (2) & .135 & .309 & .192 & 1 & .661 & 1.145 & .625 & 2.098 \\
\hline Online review reading & & & 34.132 & 4 & .000 & & & \\
\hline $\begin{array}{l}\text { Online review reading } \\
\text { (1) }\end{array}$ & 2.674 & .634 & 17.778 & 1 & .000 & 14.492 & 4.182 & 50.222 \\
\hline $\begin{array}{l}\text { Online review reading } \\
\text { (2) }\end{array}$ & 3.335 & .623 & 28.622 & 1 & .000 & 28.077 & 8.275 & 95.270 \\
\hline $\begin{array}{l}\text { Online review reading } \\
\text { (3) }\end{array}$ & 2.845 & .647 & 19.360 & 1 & .000 & 17.209 & 4.845 & 61.124 \\
\hline $\begin{array}{l}\text { Online review reading } \\
\text { (4) }\end{array}$ & 3.343 & .645 & 26.870 & 1 & .000 & 28.306 & 7.997 & 100.193 \\
\hline review_indepth (1) & 2.011 & .294 & 46.762 & 1 & .000 & 7.474 & 4.199 & 13.302 \\
\hline photos_inreview (1) & -.860 & .270 & 10.126 & 1 & .001 & .423 & .249 & .719 \\
\hline Constant & -3.286 & .800 & 16.869 & 1 & .000 & .037 & & \\
\hline
\end{tabular}

a. Variable(s) entered on step 1: Hours daily, Access place, Access medium, online review reading, review_indepth, photos_inreview.

Table no 10 shows the results of the research model analysis. The proposed relationship between hours daily and gist helpfulness was significant (Wald $\chi^{2}=17.439, \mathrm{p}<0.001$ ), thus supporting H1a. The relationship between Access place and gist helpfulness was not significant (Wald $\chi^{2}=3.255, \mathrm{p}=.412$ ). Therefore, we don't find support for H1c. The relationship between Access medium and gist helpfulness was not significant (Wald $\chi^{2}=.269, \mathrm{p}=.874$ ). Thus, $\mathrm{H} 1 \mathrm{~b}$ is not supported. The proposed relationship between online review reading experience and gist helpfulness was significant (Wald $\chi^{2}=34.132, \mathrm{p}<$ 0.001 ), thus supporting H2c. The relationship between review in depth and gist helpfulness was significant (Wald $\chi^{2}=46.762, \mathrm{p}<0.001$ ), thus supporting H2a. The relationship between photos in review and gist helpfulness was significant (Wald $\chi^{2}=10.126, \mathrm{p}<0.001$ ) but the coefficient was negative $(b=-.860)$, thus $\mathrm{H} 2 \mathrm{~b}$ is not supported. Table no 11 summarizes the hypothesis testing.

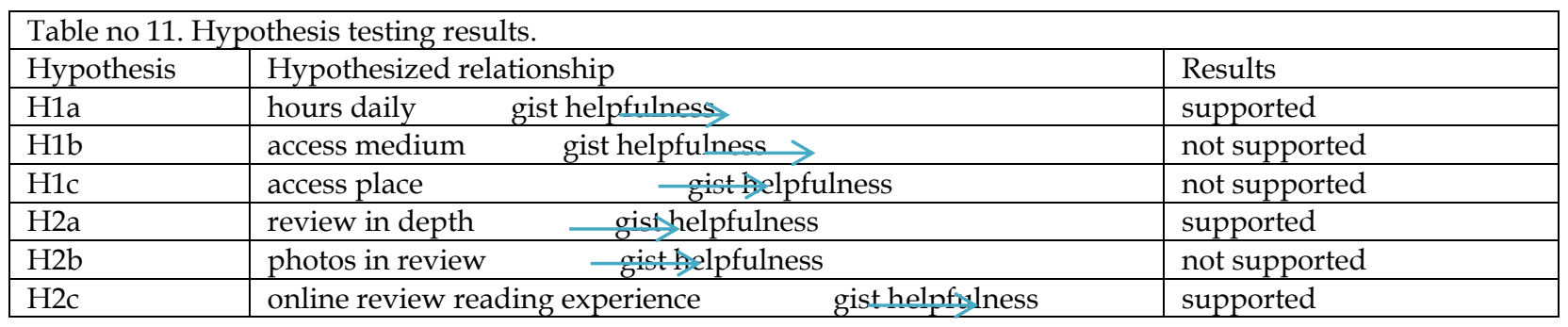

Table no 12. Classification Plot 

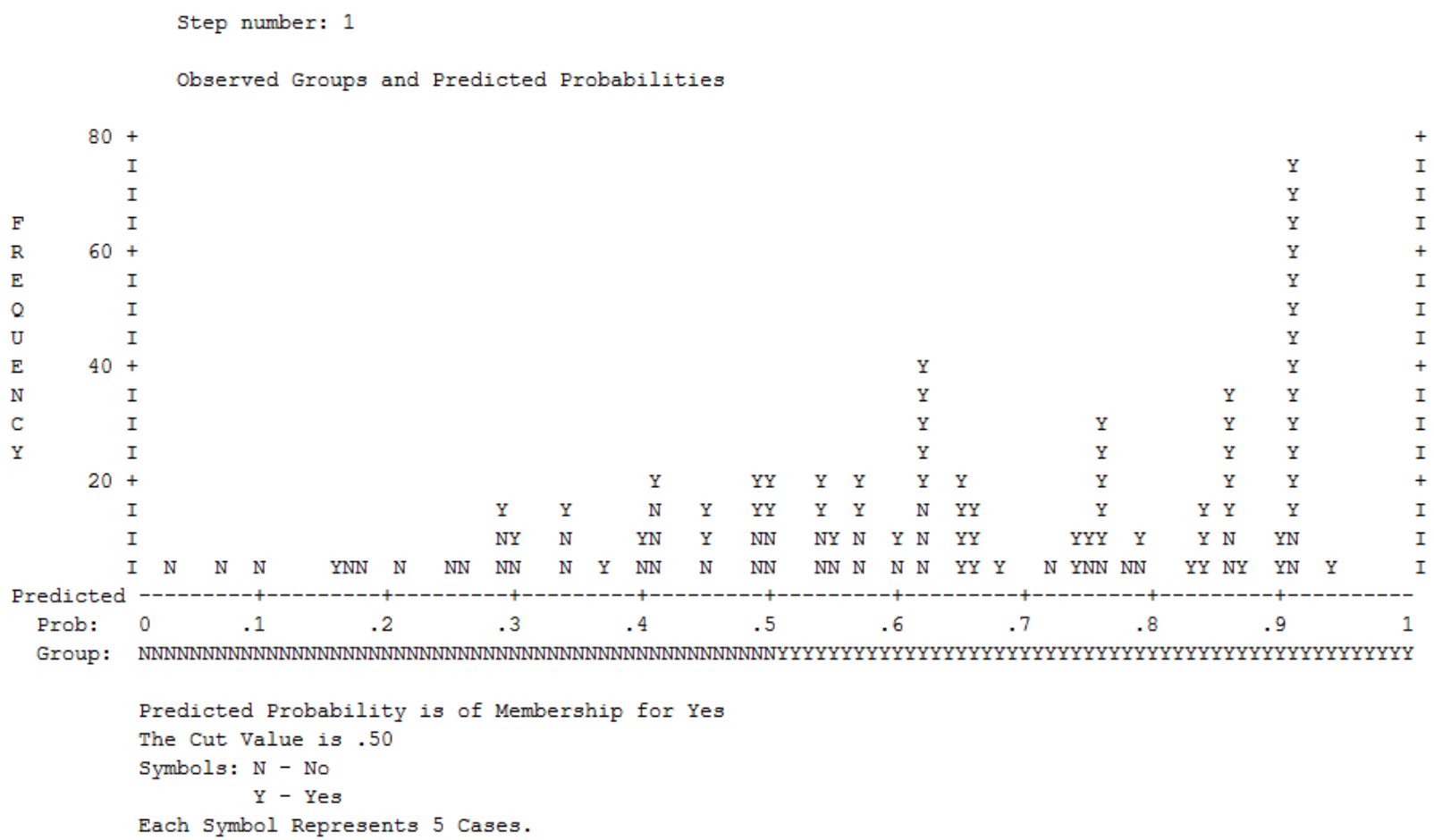

Table no 12 shows the classification plot for Yes. The plot does not indicate normal distribution, thus is a good model fit.

\section{Discussion and Conclusion}

From table no 10 we have the $\operatorname{Exp}(\mathrm{B})$ column which represents the odds ratio. Hours daily is significant which represents consumers using internet less than an hour daily $(p<0.001)$. They are users with limited resources such as time and bound to get straight to the work when they online. They may barely have time to read anyone's reviews and may rely on ratings of the product. The gist model may help them to make decision split seconds at times. Zhu and Zhang (2010) found that there can be a positive association between the reliance on online reviews and a consumers' Internet experience. Hours daily (2) represents users with 3-4 hours, have $\operatorname{Exp}(B)=2.549$. We can take $\operatorname{Exp}(B)$ in terms of the change in odds. If the value surpasses 1 then the odds of an outcome occurring increases. Therefore, users who use internet 3-4 hours daily 2.5 more times likely find the gist model helpful. One of the reasons for the above may be that being online enough they have ability understand and adapt themselves to a new online feature quickly. Although Hours daily (2) is insignificant $(\mathrm{p}=.069)$. online review reading (4) is significant which represents consumers prefer to read more than 10 reviews before buying product online $(\mathrm{p}<0.001)$, has $\operatorname{Exp}(\mathrm{B})=$ 28.306. Therefore, users who read more than 10 online reviews are 28 more times likely find the gist model helpful. review_indepth (1) is significant which represents consumers prefer to read lengthy reviews for products $(\mathrm{p}<0.001)$, has $\operatorname{Exp}(\mathrm{B})=7.474$.

Therefore, users who prefer to read lengthy online reviews are 7 more times likely find the gist model helpful. The users in these brackets could be said that they are inquisitive in nature. They want to be sure of what they are buying. They prefer to read lengthy and a greater number of reviews until their sentiment meter is filled with positive sentiments about the product. They find gist model helpful as we have tried to summarize the sentiments in reviews by means of formation of title. photos_inreview(1) is significant which represents consumers prefer photos in reviews of products $(p<0.001)$, has $\operatorname{Exp}(B)=$ $.423 . \operatorname{Exp}(\mathrm{B})$ figure is less than 1 that is any increase in the predictor will lead to a drop in the odds of the outcome occurring i.e. may not find gist model helpful. The variable has negative effect on outcome despite being significant. Photos depict first hand clear clue about the product bought online. Therefore, the consumer may not solely rely on gist model. 


\section{Managerial Implications}

The study attempts to eliminate the sentiments created by user generated title of reviews i.e. positive, negative, mixed sentiments. The study moves in the direction of making titles more rational and not emotion-based titles. This study also contributes to the form of knowledge by studying readership and helpfulness of online reviews. The study provides improvement and help consumers for selection for reading reviews and ignoring other reviews based on the title of reviews. The titles may be classified into four dimensions represented by symbols with the help of online review indicator (execution, price, maintenance, and feature). Thus, person recommending a product; the title of review has four dimensions. One can select all dimensions or any of the four.

A person who is keen to buy a smartphone online may be sure of quality of the smartphone i.e. Aluminum case, $9 \mathrm{H}$ hardness glass for screen but not so sure about performance. The person may inherit selective approach of reading reviews that recommend the smartphone based on performance. A person who wants to buy electric shaver may select the approach of reading reviews that has recommended electric shaver based on service provided by the company. The person may have doubt if the blades or motor of the shaver wears out within warranty period does the company provide replacement or not. Thus, the study adds in direction of making online reviews more targeted to interested audience in specific contexts (execution, price, maintenance, and feature) of a product rather than audience. The study of gist helpfulness provides vital information in the titles of review such as name of the user, recommendation, longevity of the review. The name reveals the identity of the user and indirectly shows that the purchase is a verified purchase or a certified buyer. It adds to the credibility of title of review. The word recommendation in the title puts forward that the product has approval from the users, as being suitable for a particular purpose or a role. The study ventures to integrate sense of giving "personal recommendation" through titles of reviews from one person to another in online ecosystem. The "days" element in online reviews is often overlooked or is undervalued. Today we live in "Update Era" for example new editions of books are released in addition to studies with respect to the current scenario the age of social media, software's are updated timely such as "Windows 10 Creators Update version 1703", and video games are patched after releases such as "The Witcher 3 update 1.31". The released product today may not be assumed as the final product like it used to be in good old-fashioned days. Nowadays the products are tweaked accordingly based on experience of consumers and so as the reviews and ratings for the product changes with time accordingly. The "days" element in title of reviews suggests a cue what is the current status of the product on this day whether you should go for it or not.

\section{Limitations and Future research}

This study suffers from several limitations. Although this study has been conducted at the individual level of analysis the actual purchase behavior may vary. Thus, the sample may not be representative of the general population of online shoppers. The analytical results exhibited here thus may have limited generalizability. Second, our conclusion does not focus on product types in this study i.e. search and experience. Future research can use a sample focusing on specific product types such as books; electronic products and test and compare the results between categories for the research model. Third, our model does not include review extremity; we cannot explain the effect of review extremity on actual purchase behavior with our model. Moambe and Schiff (2010) have suggested that product type mediates the effect of review extremity on the helpfulness of the review. Future research could empirically examine the effect review extremity on our model. Finally, since the sample was collected in India, generalizability to other countries might be limited due to cultural differences in purchase behaviors.

\section{References}

Beak, H., An, J. and Choi, Y. (2012), "Helpfulness of Online Consumer Reviews: Readers' Objectives and Review Cues", International Journal of Electronic Commerce, Vol. 17 No. 2, pp. 99-126.

Cao, Q., Duane, W. and Gan, Q. (2011), "Exploring determinants of voting for the "helpfulness" of online user reviews: A text mining approach", Decision Support Systems, Vol. 50 No. 2, pp. 511-521.

Chen, P., Dhanesh, S. and Smith, M. (2008). "All Reviews are Not Created Equal: The Disaggregate Impact of Reviews and Reviewers at Amazon.Com", SSRN Electronic Journal, doi:10.2139/ssrn.918083.

Chen, P.Y., Wu, S.Y. and Yoon, J. (2004). "The impact of online recommendations and consumer feedback on sales". ICIS 2004 Proceedings, p.58. 
Chevalier, J. and Mazlan, D. (2006), "The Effect of Word of Mouth on Sales: Online Book Reviews", Journal of Marketing Research, Vol. 43 No. 3, pp. 345-354.

Cheung, C.M.Y., Sia, C.L. and Kuna, K.K. (2012). "Is this review believable? A study of factors affecting the credibility of online consumer reviews from an ELM perspective". Journal of the Association for Information Systems, Vol. No.8, pp. 618-635.

Cui, G., Lui, H. and Guo, X. (2012), "The Effect of Online Consumer Reviews on New Product Sales", International Journal of Electronic Commerce, Vol. 17 No. 1, pp. 39-58.

Dellarocas, C. (2003), "The Digitization of Word of Mouth: Promise and Challenges of Online Feedback Mechanisms", Management Science, Vol. 49 No. 10, pp. 1407-1424.

Dellarocas, C., Zhang, X. and Awad, N. (2007), "Exploring the value of online product reviews in forecasting sales: The case of motion pictures", Journal of Interactive Marketing, Vol. 21 No. 4, pp. 23-45.

Dellarocas, C. (2006), "Strategic Manipulation of Internet Opinion Forums: Implications for Consumers and Firms", Management Science, Vol. 52 No. 10, pp. 1577-1593.

Duan, W., Gu, B. and Whinston, A. (2008), "Do online reviews matter? - An empirical investigation of panel data", Decision Support Systems, Vol. 45 No. 4, pp. 1007-1016.

En.wikipedia.org. (2016), "Gestalt psychology", available at: https://en.wikipedia.org/wiki/Gestalt_psychology (accessed 8 November 2016).

Fagerstrøm, A. and Ghinea, G. (2011), "On the motivating impact of price and online recommendations at the point of online purchase", International Journal of Information Management, Vol. 31 No. 2, pp. 103-110.

Forman, C., Ghose, A. and Wiesenfeld, B. (2008), "Examining the Relationship Between Reviews and Sales: The Role of Reviewer Identity Disclosure in Electronic Markets", Information Systems Research, Vol. 19 No. 3, pp. $291-313$.

Ghose, A. and Ipeirotis, P. (2011), "Estimating the Helpfulness and Economic Impact of Product Reviews: Mining Text and Reviewer Characteristics", IEEE Transactions on Knowledge and Data Engineering, Vol. 23 No. 10, pp. 14981512.

Godes, D. and Mayzlin, D. (2004), "Using Online Conversations to Study Word-of-Mouth Communication", Marketing Science, Vol. 23 No. 4, pp. 545-560.

$\mathrm{Hu}$, N., Bose, I., Koh, N. and Liu, L. (2012), "Manipulation of online reviews: An analysis of ratings, readability, and sentiments", Decision Support Systems, Vol. 52 No. 3, pp. 674-684.

$\mathrm{Hu}$, N., Liu, L. and Zhang, J. (2008), "Do online reviews affect product sales? The role of reviewer characteristics and temporal effects", Information Technology and Management, Vol. 9 No. 3, pp. 201-214.

Jiménez, F. and Mendoza, N. (2013), "Too Popular to Ignore: The Influence of Online Reviews on Purchase Intentions of Search and Experience Products", Journal of Interactive Marketing, Vol. 27 No. 3, pp. 226-235.

Korfiatis, N., García-Bariocanal, E. and Sánchez-Alonso, S. (2012), "Evaluating content quality and helpfulness of online product reviews: The interplay of review helpfulness vs. review content", Electronic Commerce Research and Applications, Vol. 11 No. 3, pp. 205-217.

Kusumasondjaja, S., Shanka, T. and Marchegiani, C. (2012), "Credibility of online reviews and initial trust: The roles of reviewer's identity and review valence", Journal of Vacation Marketing, Vol. 18 No. 3, pp. 185-195.

Lee, J., Park, D. and Han, I. (2011), "The different effects of online consumer reviews on consumers' purchase intentions depending on trust in online shopping malls", Internet Research, Vol. 21 No. 2, pp. 187-206.

Li, M., Huang, L., Tan, C. and Wei, K. (2013), "Helpfulness of Online Product Reviews as Seen by Consumers: Source and Content Features", International Journal of Electronic Commerce, Vol. 17 No. 4, pp. 101-136.

Liu, Y. (2006), "Word of Mouth for Movies: Its Dynamics and Impact on Box Office Revenue", Journal of Marketing, Vol. 70 No. 3, pp. 74-89.

Liu, Z. and Park, S. (2015), "What makes a useful online review? Implication for travel product websites", Tourism Management, Vol. 47, pp. 140-151.

Luca, M. and Zervas, G. (2016), "Fake It till You Make It: Reputation, Competition, and Yelp Review Fraud", Management Science, doi:10.1287/mnsc.2015.2304.

Mayzlin, D., Dover, Y. and Chevalier, J. (2014), "Promotional Reviews: An Empirical Investigation of Online Review Manipulation", American Economic Review, Vol. 104 No. 8, pp. 2421-2455.

McAuley, J.J. and Leskovec, J. (2013), "From amateurs to connoisseurs: modeling the evolution of user expertise through online reviews". In Proceedings of the 22nd international conference on World Wide Web (pp. 897-908). ACM.

Mudambi, S. M., and Schuff, D. (2010). “What Makes a Helpful Online Review? A Study of Customer Reviews on Amazon.Com," MIS Quarterly, Vol. 34 No. 1, pp. 185-200.

Park, D., Lee, J. and Han, I. (2007), "The Effect of On-Line Consumer Reviews on Consumer Purchasing Intention: The Moderating Role of Involvement", International Journal of Electronic Commerce, Vol. 11 No. 4, pp. 125-148. 
Racherla, P. and Friske, W. (2012), "Perceived 'usefulness' of online consumer reviews: An exploratory investigation across three services categories", Electronic Commerce Research and Applications, Vol. 11 No. 6, pp. 548-559.

Salehan, M. and Kim, D. (2016), "Predicting the performance of online consumer reviews: A sentiment mining approach to big data analytics", Decision Support Systems, Vol. 81, pp. 30-40.

Schindler, R. and Bickart, B. (2012), "Perceived helpfulness of online consumer reviews: The role of message content and style", Journal of Consumer Behaviour, Vol. 11 No. 3, pp. 234-243.

Schlosser, A. (2011), "Can including pros and cons increase the helpfulness and persuasiveness of online reviews? The interactive effects of ratings and arguments", Journal of Consumer Psychology, Vol. 21 No. 3, pp. 226-239.

Senecal, S. and Nantel, J. (2004), "The influence of online product recommendations on consumers' online choices", Journal of Retailing, Vol. 80 No. 2, pp. 159-169.

Treisman, A. (1969), "Strategies and models of selective attention.", Psychological Review, Vol. 76 No. 3, pp. $282-299$.

Xia, L. and Bechwati, N. (2008), "Word of Mouse", Journal of Interactive Advertising, Vol. 9 No. 1, pp. 3-13.

Xie, H., Miao, L., Kuo, P. and Lee, B. (2011), "Consumers' responses to ambivalent online hotel reviews: The role of perceived source credibility and pre-decisional disposition", International Journal of Hospitality Management, Vol. 30 No. 1, pp. 178-183.

Yin, D., Bond, S. and Zhang, H. (2014). "Anxious or angry? Effects of discrete emotions on the perceived helpfulness of online reviews". Mis Quarterly, Vol. 38 No. 2, pp.539-560.

Zhang, J., Craciun, G. and Shin, D. (2010), "When does electronic word-of-mouth matter? A study of consumer product reviews", Journal of Business Research, Vol. 63 No. 12, pp. 1336-1341.

Zhang, X. and Dellarocas, C. (2006). “The Lord of The Ratings: Is A Movie's Fate is Influenced by Reviews?”. ICIS 2006 Proceedings, p.117.

Zhu, F. and Zhang, X. (2010), "Impact of Online Consumer Reviews on Sales: The Moderating Role of Product and Consumer Characteristics", Journal of Marketing, Vol. 74 No. 2, pp. 133-148.

Zhu, L., Yin, G. and He, W. (2014). "Is this opinion leader's review useful? Peripheral cues for online review helpfulness". Journal of Electronic Commerce Research, Vol. 15 No. 4, pp.267-280.

\begin{tabular}{|c|c|c|c|c|c|c|}
\hline \multicolumn{7}{|c|}{ 9. Appendix A: Categorical Variables Coding } \\
\hline & & \multirow[t]{2}{*}{ Frequency } & \multicolumn{4}{|c|}{ Parameter coding } \\
\hline & & & (1) & (2) & (3) & $(4)$ \\
\hline Hours daily & Less than 1 hour (Reference group) & 24 & .000 & .000 & .000 & .000 \\
\hline Hours daily (1) & 1-2 hours & 156 & 1.000 & .000 & .000 & .000 \\
\hline Hours daily (2) & 3-4 hours & 180 & .000 & 1.000 & .000 & .000 \\
\hline Hours daily (3) & 5-6 hours & 64 & .000 & .000 & 1.000 & .000 \\
\hline Hours daily (4) & more than 6 hours & 104 & .000 & .000 & .000 & 1.000 \\
\hline online review reading & No reviews (Reference group) & 28 & .000 & .000 & .000 & .000 \\
\hline $\begin{array}{l}\text { online review reading } \\
\text { (1) }\end{array}$ & g1- 3 reviews & 136 & 1.000 & .000 & .000 & .000 \\
\hline $\begin{array}{l}\text { online review reading } \\
(2)\end{array}$ & g4-7 reviews & 184 & .000 & 1.000 & .000 & .000 \\
\hline $\begin{array}{l}\text { online review reading } \\
\text { (3) }\end{array}$ & g7-10 reviews & 80 & .000 & .000 & 1.000 & .000 \\
\hline $\begin{array}{l}\text { online review reading } \\
(4)\end{array}$ & gmore than 10 reviews & 100 & .000 & .000 & .000 & 1.000 \\
\hline Access medium & PC (Reference group) & 80 & .000 & .000 & & \\
\hline Access medium (1) & Tablet & 8 & 1.000 & .000 & & \\
\hline Access medium (2) & Smartphone & 440 & .000 & 1.000 & & \\
\hline review_indepth & No (Reference group) & 312 & .000 & & & \\
\hline review_indepth (1) & Yes & 216 & 1.000 & & & \\
\hline Access place & At home (Reference group) & 456 & .000 & & & \\
\hline Access place (1) & At work & 72 & 1.000 & & & \\
\hline photos_inreview & No (Reference group) & 188 & .000 & & & \\
\hline photos_inreview (1) & Yes & 340 & 1.000 & & & \\
\hline
\end{tabular}

